This is the final author's version of the article published in JASIST:

Gwizdka, J., \& Lopatovska, I. (2009). The role of subjective factors in the information search process. Journal of the American Society for Information Science and Technology. 60(12). (doi:10.1002/asi.21183)

\title{
The Role of Subjective Factors in the Information Search Process
}

Jacek Gwizdka, PhD

Assistant Professor

LIS, SC\&I

Rutgers University

4 Huntington St.

New Brunswick, NJ 08901

+1 $7329327500 \times 8236$

jasist@gwizdka.com

[Corresponding author]

Irene Lopatovska, PhD Candidate

Assistant Professor

SILS

Pratt Institute

144 w. 14th street, 6th floor

New York, NY 10011-7301

ilopatov@pratt.edu

\section{Abstract}

We investigated the role of subjective factors in the information search process. Forty eight participants each conducted six web searches in a controlled setting. We examined relationships between subjective factors (happiness levels, satisfaction with and confidence in the search results, feeling lost during search, familiarity with and interest in the search topic, estimation of task difficulty), and objective factors (search behavior, search outcomes and search task characteristics). Data analysis was conducted using a multivariate statistical test (Canonical Correlations Analysis). The findings confirmed existence of several relationships suggested by prior research, including relationships between objective search task difficulty and the perception of task difficulty; between subjective states and search behaviors and outcomes. One of the original findings suggests that higher happiness levels before the search and during the search correlate with better feelings after the search, but also correlates with worse search outcomes and lower satisfaction, suggesting that, perhaps, it pays off to feel some 'pain' during the search in order to 'gain' quality outcomes.

\section{Introduction}

Library and Information Science (LIS) research has recognized the importance of subjective variables in an information search process. Emotions, affect, feelings and perceptions have been shown to influence search strategies, performance and satisfaction. Our study extended the line of previous inquiries into the role of subjective variables in the information search process by examining the relationships between subjective variables, search behavior, search outcomes, characteristics of the search task and familiarity with the search system and its interface. 
Subjective aspects of information searching can be defined very broadly to include all aspects related to users' feelings and perceptions (in contrast to their actions directed towards the system in achieving their goal). A large number of studies addressed various aspects of this broad approach. These include studies of searchers' feelings associated with the search stages (Kuhlthau, 1991), searchers' satisfaction (Tessier, Crouch, \& Atherton, 1977; Su, 2003), satisficing (Marchionini, 1995; Agosto, 2002) and relevance judgments (Saracevic, 2007). While our research was influenced by this larger context of subjective factors, our interest was focused on specific subjective variables. The primary goal of the study was to examine searchers behavior while monitoring changes of their 'subjective' states, specifically effects of changing search circumstances on the searchers feelings and experiences..

In this paper, we refer to ratings that were self-reported by searchers as "subjective factors". This broad term includes affective (e.g., positive and negative feelings), cognitive (e.g., perception of being lost), and evaluative (e.g., judgment of task difficulty) measures that reflected searchers perceptions of self and the search environment.

We start by reviewing previous studies that informed our conceptual model and influenced the selection of the study variables. We then propose a conceptual model that describes the role of subjective variables in the search process; we describe our experimental method used for exploring the model, and, finally, we present the results and a refined model informed by our research.

\section{Related Research}

A large number of information science studies examined relationships between searchers' subjective states and their search behavior. We review studies that particularly influenced our conceptual model and the selection of specific variables used in the study.

One of the most popular ways to gauge searchers' subjective states is asking them how they feel. Positive and negative feelings have been shown to influence search performance and be influenced by interface features, search process, and results. The study of inexperienced searchers (Meghabghab, 1995) reported an increase of positive feelings as searchers acquired knowledge of particular search techniques and became more successful in their searching. Wang, Hawk and Tenopir (2000) examined cognitive and affective aspects of search behavior on the web and found reciprocal relationships between affect and search performance. The study findings indicated that positive feelings supported subsequent interactions with a system while negative feelings hindered the search process. Positive feelings were found to be related to a successful action, while negative feelings were found to be related to the participants' inability to find answers to the questions. A study of children's use of a search engine (Bilal, 2000) found that participants' positive feelings were associated with the ease of use and fun associated with the use of a web browser. In a study of children's interaction with the International Children's Digital Library, Bilal and Bachir (2007) discovered that children had positive experiences with the digital library and liked the library because they could learn something new and see beautiful things there. Positive feelings were associated with the easiness of use and effective navigation. Negative feelings were associated with the limited size of electronic collection. Lopatovska and 
Mokros (2007) examined how searchers' willingness to pay for the found web sites correlated with their feelings (positive/negative) regarding the sites. The study found that participants felt better and were willing to pay more for the web sites that provided answers to the search question. The study also found that searchers felt better after reading web sites that they described as stylistically pleasing, interesting, and useful.

Another way of monitoring subjective states is asking participants how happy they feel. This measure is not popular in library and information science research, but it is widely used for measuring well-being in psychology. The measure of "objective happiness" is derived by asking participants to report their current levels of happiness/unhappiness, pleasure or pain (Kahneman, 2000). The method was used to study well-being of people living in California and Midwest (Schkade \& Kahneman, 1998), patients having a colonoscopy procedure (Redelmeier \& Kahneman, 1996), experimental subjects listening to different sounds (Schreiber \& Kahneman, 1996), and other studies. The momentary reports are considered more accurate than retrospective reports; they offer an efficient and easy way of monitoring affective states (Kahneman, 2000)

Several studies examined relationships between search performance, evaluative and affective variables using a number of specific variables, including successful task completion, the amount of time spent on the task, search outcomes, searching skills, task difficulty level, interest in the process or a document and satisfaction, confidence, and other feelings. Nahl (1998) reviewed the information behavior literature describing cognitive and affective components of searching and found evidence of the relationships between affective variables (e.g., satisfaction, selfconfidence, doubt, hope, felt difficulty, frustration) and search motivation, performance, and satisfaction. Bilal and Kirby (2002) compared the internet search behavior of adults and children and showed that both groups experienced satisfaction and comfort with the successful completion of the task, while both groups experienced frustration due to difficulties with finding the answer. In the study of inexperienced searchers (Meghabghab, 1995), negative affect and dissatisfaction were linked to difficulties in conducting searches due to the lack of knowledge and experience. As searchers gained searching skills and confidence, their searching improved and satisfaction levels increased. Wang, Hawk and Tenopir (2000) also found that successful search performance reduced negative feelings, such as anxiety. Nahl (2005) investigated the effects of affective variables on search behavior and found self-efficacy and optimism increased user support and acceptance of the system. Self-efficacy and optimism were also linked to increased motivation to complete the task and higher satisfaction rates (Nahl, 2004). Researchers found positive correlation between self-efficacy, satisfaction and optimism and better search performance (Nahl \& Meer, 1997). In a study that explored affective and cognitive aspects of the searching behavior of novice users, Nahl and Tenopir (1996) found that hesitation, need for confirmation, fear, surprise and other feelings affected search strategies. While examining internet learning behavior, James and Nahl (1996) noticed that the feeling of difficulty was linked to making mistakes (typing mistakes or omissions) and satisfaction was felt when corrections were made. Kracker (2002) and Kracker and Wang (2002) discovered that positive emotions were associated with confidence and interest in the search process and the documents. A study of affective valuation of electronic documents (Lopatovska \& Mokros, 2007) found that interest in a document and document's stylistic properties were positively correlated with participants' self-reported positive and negative feelings. 
Perception of search task difficulty has been shown to be affected by the searchers' behavior. Gwizdka and Spence demonstrated in two studies $(2006,2007)$ that the searchers' a posteriori assessment of task difficulty was positively correlated with their effort and efficiency on these tasks. In the two studies, the effort was measures as the number of web pages visited, while efficiency was represented as the time spent on each page and the linearity of the searcher's navigation path. Tzeng (2004) found that the game's difficulty level was the most important predictor of participants' satisfaction with the game. Playing an easier game resulted in better overall performance and generated feelings of gratification and confidence in playing the game, better feelings about the program and confidence in future success. In the study of senior college students' information behavior (Nahl, 2005), perceived difficulty was found to influence uncertainty, expected effort and motivation to complete the search task.

The findings of prior research into the role of subjective variables in a search process are summarized in Table 1. The relationships that were suggested by the prior research are visually represented in a conceptual framework (Figure 1). The framework illustrates the relationships between the groups of search variables that were correlated with subjective variables reported before, during and after the search.

Table 1. Summary of Prior Findings on the Role of Subjective Variables in the Search Process

\begin{tabular}{|c|c|c|c|}
\hline Index & $\begin{array}{c}\text { Subjective } \\
\text { variables } \\
\text { measured }\end{array}$ & Related to & Research that found the relationships \\
\hline $\mathbf{a}$ & \multirow{3}{*}{$\begin{array}{l}\text { before } \\
\text { search }\end{array}$} & search behavior & $\begin{array}{l}\text { Nahl \& Tenopir, 1996; Nahl \& Meer, 1997; Nahl, 2005; Kracker, } \\
\text { 2002; Kracker \& Wang, 2002; Lopatovska \& Mokros, } 2007\end{array}$ \\
\hline b & & search outcomes & Mellon, 1988; Onwuegbuzie \& Jiao, 2004 \\
\hline c & & feelings after the search & Nahl, 1998; Wang, Hawk and Tenopir, 2000 \\
\hline d & \multirow{4}{*}{$\begin{array}{l}\text { during \& } \\
\text { after } \\
\text { search }\end{array}$} & search outcomes & Bilal \& Kirby, 2002 \\
\hline e & & search behavior & Wang, Hawk and Tenopir, 2000; Gwizdka \& Spence, 2006 \& 2007 \\
\hline $\mathbf{f}$ & & system design features & Bilal, 2000; Bilal \& Bachir, 2007; Kalbach, 2006; Tractinsky, 2004 \\
\hline g & & task characteristics & Gwizdka \& Spence, 2006 \& 2007 \\
\hline
\end{tabular}




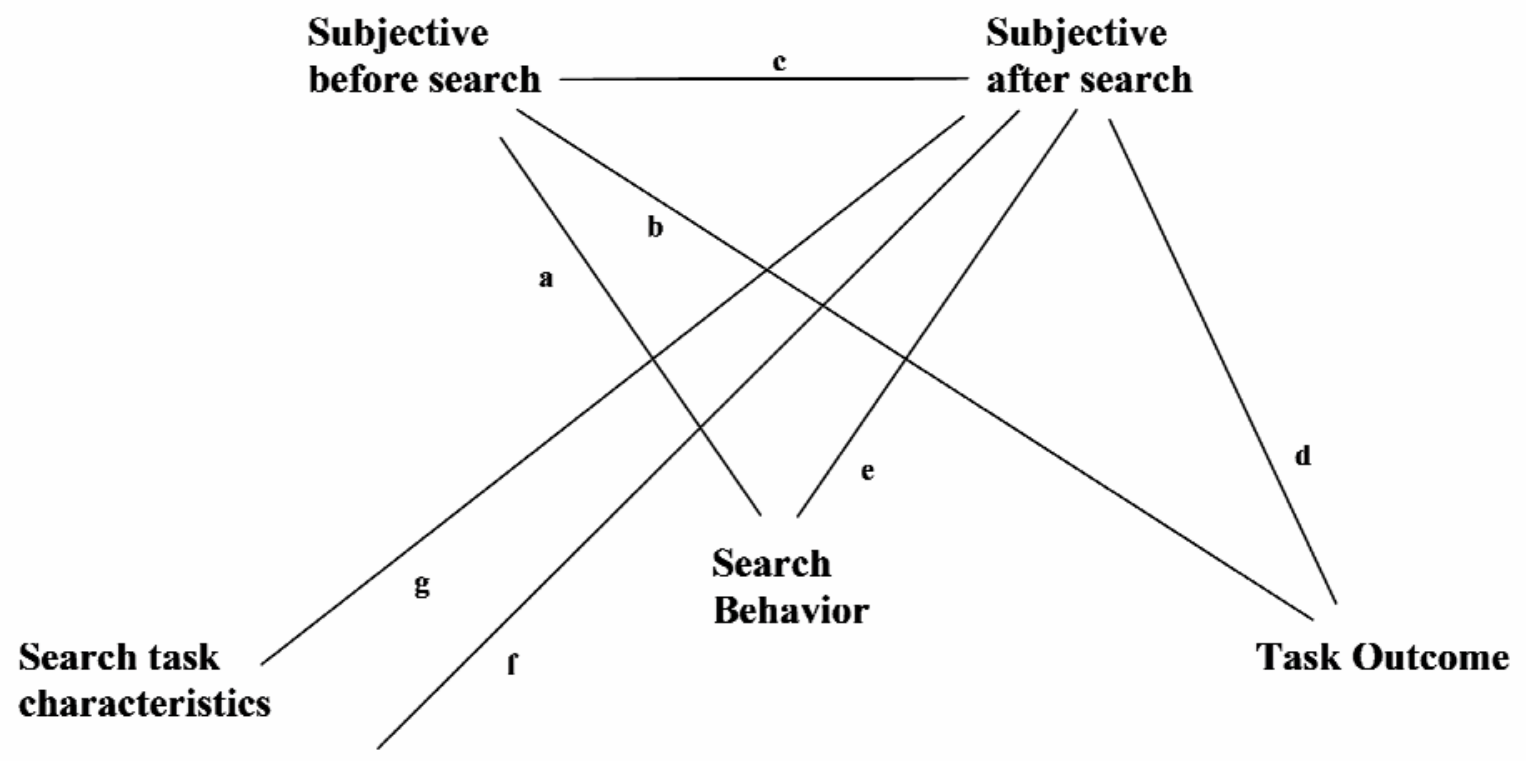

Search system

\& interface

Figure 1. The Role of Subjective Variables in the Information Search Process - a conceptual framework based on prior research. The letters index the relationships according to their presentation in the Related Research section.

The conceptual framework guided our exploratory investigation of relationships between the groups of variables. The investigation of subjective factors was part of an inquiry that examined task characteristics and user behavior on Web search tasks. Other aspects of the study that are not reported in this article were concerned with the analysis at a more detailed level of task stages and examined the structure and attributes of user navigation graphs (the findings will be reported in a separate article). The next section describes the study method, factors that were controlled in the study (search task and search interface), and variables that were used to represent search behavior, search outcomes, and subjective factors before and after the search task.

\section{Method}

\section{Participants}

Forty eight subjects (Table 2) participated in question-driven, web-based information search study conducted in a controlled experimental setting. Participants were recruited from Rutgers University student population enrolled in undergraduate and graduate programs offered by the School of Communication, Information and Library Studies (an undergraduate program in Information Technology and Informatics, a graduate MLIS program and a $\mathrm{PhD}$ program). Participants were offered a monetary incentive (\$20); participants who were recruited from an undergraduate $\mathrm{HCI}$ class received a partial course credit. Participants were motivated to find the requested information by a bonus worth one third of the standard incentive. The bonus was 
administered to one third of the participants after the experiment was completed and the task outcomes measures were calculated. Most participants were very frequent web searchers and only one person searched once or twice a week (Table 2).

Table 2. Participants Profile

\begin{tabular}{ll}
\hline Age & Mean 27 year; median 23 years. range 20-51 \\
\hline Gender & 17 females and 31 males. \\
\hline Current level of study & Undergraduate $65 \%$; Master $6 \% ;$ PhD $23 \% ;$ Other (just graduated) $6 \%$ \\
\hline English language & First language $56 \% ;$ spoken at home $65 \%$ \\
\hline Web search frequency & $35 \%$ almost constantly; $46 \%$ several times a day; $17 \%$ once a day; $2 \%$ once or twice a week. \\
\hline
\end{tabular}

\section{User Tasks}

The study search tasks were designed as questions that described what information needed to be found and provided a context for the search. The tasks were designed to differ in terms of their difficulty and structure. The total of twelve questions were used in the study. Four tasks were created by the authors, while eight were created by Toms and her colleagues (2008). Two types of search tasks were used: Fact Finding (FF) and Information Gathering (IG) (Kellar, Watters \& Shepherd, 2007). The goal of a fact finding task is to find one or more specific pieces of information (e.g., name of a person or an organization, product information, a numerical value; a date). This type of task is also referred to as a known item search (Li \& Belkin, 2008). The goal of an information gathering task is to collect several pieces of information about a given topic. This type of task is also referred to as a topical search. The tasks were also divided into three categories that depended on the structure of the underlying information need, 1) Simple (S), where the information need is satisfied by a single piece of information (by definition, simple task is of fact finding type); 2) Hierarchical $(\mathrm{H})$, where the information need is satisfied by finding multiple characteristics of a single concept (a depth search); 3) Parallel (P), where the information need is satisfied by finding multiple concepts that exist at the same level in a conceptual hierarchy (a breadth search). The tasks were constructed according to Situated Work Task Situations (Borlund, 2003). The simulated situations were created by using task scenarios that provided participants with the search context and the basis for relevance judgments.

Table 3. Task Types and Structures.

\begin{tabular}{ll}
\hline Task Acronym & Task Description \\
\hline FF-S & Simple fact finding task (known item search) \\
\hline FF-P & Parallel fact finding task (known item search) \\
\hline FF-H & Hierarchical fact finding task (known item search) \\
\hline IG_P & Simple information gathering task (topical search) \\
\hline IG_H & Parallel information gathering task (topical search) \\
\hline
\end{tabular}

During the course of an individual study session, each participant performed six tasks of differing type and structure (Table 4). For each task, participant was able to choose between two questions of the same type and structure but on different topics. We offered the choice of topics to increase the likelihood of participants' interest in the question's topic. The order of tasks was 
balanced with respect to the objective task difficulty to obtain all possible combinations of lowmedium-high and high-medium-low difficulty within the groups of three tasks (Table 4). We used only two task orders low-medium-high and high-medium-low task difficulty, since based on prior research (Gwizdka \& Spence, 2006), we could assume that other orders of task difficulty (such as, low-high-medium, high-low-medium) are not likely to result in significant order effects. Simple fact-finding task was repeated twice (e.g, FF-S) in each rotation. To avoid repeating search topics in one task rotation, we created two groups of search topics for this task type (for the total of four).

Table 4. Task rotations (for one rotation of each search system). Numerical indexes refer to FF-S topic groups.

\begin{tabular}{ccccccc}
\hline QR / Task Seq. & TSeq1 & TSeq2 & TSeq3 & TSeq4 & TSeq5 & TSeq6 \\
\hline QR1 & FF-S1 & FF-P & IG-H & FF-S2 & FF-H & IG-P \\
\hline QR2 & IG-H & FF-P & FF-S1 & IG-P & FF-H & FF-S2 \\
\hline QR3 & FF-S1 & FF-P & IG-H & IG-P & FF-H & FF-S2 \\
\hline QR4 & IG-H & FF-P & FF-S1 & FF-S2 & FF-H & IG-P \\
\hline
\end{tabular}

The search tasks were performed on the English Wikipedia by using two different search engines: U1 - Google Wikipedia search, and U2 - ALVIS Wikipedia search (Buntine et. al. 2005). Wikipedia's own search engine was not used. U1 was familiar to study participants, while U2 was not. U1 displayed search results in a list, while U2 presented search results along with their categories and allowed for category-based browsing of results. Care was taken to ensure that the content of all Wikipedia pages that were visited by study participants was the same or differed negligibly across all the study sessions.

The search engine (along with the associated interface) was switched after task 3 . The four task rotations (Table 4) were repeated for two orders of user interfaces (U1/U2 and U2/U1). Thus there were a total of eight combined rotations of tasks and UIs for each participant.

\section{Procedure}

Each study session took an hour and a half to two hours and was conducted in a university lab on a personal desktop computer running Microsoft Windows XP operating system. Each session consisted of the following steps: introduction to the study, consent form, search task practice, background questionnaire, six search tasks, and post-session questionnaire (Figure 2). Before and after each search task, participants answered a short set of questions to provide subjective assessments of their feelings and task characteristics. Questions asked after the task also prompted participants to assess their feelings about task performance (feeling of lostness, confidence, satisfaction). All questions are described in detail in the section presenting Subjective variables and are listed in the Appendix. The searchers bookmarked and tagged the web pages that they considered to be relevant. User interaction with computer (visited and bookmarked URLs, mouse and keyboard events, and screen cam) was recorded using Morae software. The start and end of each search task were controlled by an external program that was used to start and end a Web browser (Internet Explorer). The same program was used to log task start and end times. Total time on a task included the searcher's bookmarking activity. 


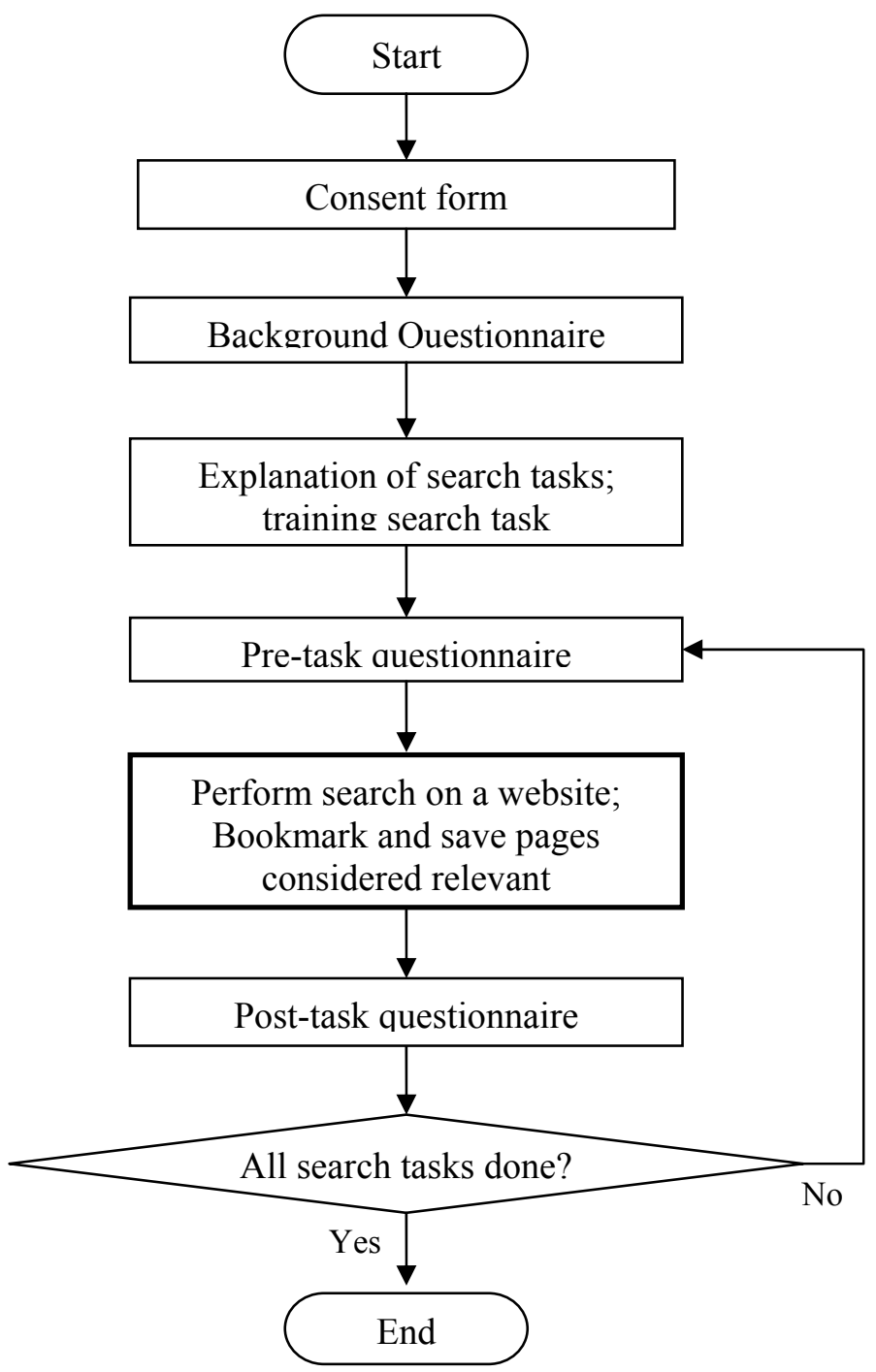

Figure 2. Study Procedure.

\section{Independent Factors (IF)}

As presented above, the controlled factors included the search task characteristics and the search system interface (see Table 5 for the list of specific independent factors variables and their descriptions).

Table 5. Independent factors (IF).

\begin{tabular}{cll}
\hline Variable Group & Variable Name & \multicolumn{1}{c}{ Variable Description and Scale } \\
\hline \multirow{2}{*}{ Task Characteristics } & q_FF_IG & Task type: $1=$ FF, 2=IG \\
\cline { 2 - 3 } & q_SHP & Task structure: $1=$ Simple, 2=Parallel, 3=Hierarchica \\
\hline $\begin{array}{c}\text { Search System } \\
\text { Interface }\end{array}$ & ui & $\begin{array}{l}\text { Search system: } 1=\text { Google's Wikipedia search (familiar), 2=ALVIS Wikipedia } \\
\text { search (familiar) }\end{array}$ \\
\hline
\end{tabular}




\section{Dependent Variables}

\section{Behavioral measures (BE)}

The recorded, time-stamped sequence of URLs was used to calculate measures of the searcher's behavior. In particular, we were interested in the count of web pages' visits; search behaviors such as, entering search queries, viewing search results and making decisions about what pages to read; reading web pages to assess their relevance to the task question, saving pages judged as relevant and entering tags to describe these pages. The measures based on web page visit counts were calculated for each search task and, with the exception of the total number of pages visited, did not include revisits to web pages. Revisits were accounted for by calculating two derived measures: 1) ratio of page revisits and 2) stratum. The ratio of page revisits (Tauscher \& Greenberg, 1997) was calculated using the ratio of unique pages to all pages visited (total_pages) in the following way: revisit_ratio $=1$-unique_pages / total_pages. The higher the revisit ratio, the more pages were revisited. Hence, the less efficient the searcher was. The individual web pages visited by searchers and the transitions between these pages (i.e. the links followed by the searchers) form a navigation graph. In this graph, web pages are the nodes and link-transitions are the edges. Stratum (Botafogo et al., 1992) is a graph property that expresses graph's linearity. Stratum is a scalar measure that varies between zero and one; values close to zero indicate a "bushy" and less linear navigation path; values close to one indicate a nearly linear navigation path. We computed stratum for navigation graphs that corresponded to each task. Stratum was previously used to characterize searcher's behavior on web navigation tasks by McEneaney (2001), Shih et al. (2004), Herder et al. (2004), Juvina et al. (2004) and Gwizdka \& Spence (2006). We also calculated navigational speed as the average time spent on a web page. The above mentioned performance measures can be considered as belonging to two groups, Search Effort, and Search Efficiency (Gwizdka \& Spence, 2006). The last performance measure was time on task (Table 6).

Table 6. Summary of behavioral variables (BE).

\begin{tabular}{|c|c|c|}
\hline Variable Group & Variable Name & Variable Description \\
\hline \multirow{4}{*}{ Search Effort } & total_pages & total number of web pages visited \\
\hline & resList1_pages & $\begin{array}{l}\text { number of visits to first search result list pages (equal to the number of } \\
\text { queries entered, revisits to the same page were not counted) }\end{array}$ \\
\hline & content_pages & $\begin{array}{l}\text { number of content pages visited (within-page navigation was considered } \\
\text { a distinct cognitive action and thus counted as a separate page; revisits to } \\
\text { the same page were not counted) }\end{array}$ \\
\hline & bookmark & number of bookmarked individual result pages \\
\hline \multirow{3}{*}{ Search Efficiency } & revisit_ratio & ratio of revisits to web pages ( $=1$-unique pages / total_pages $)$ \\
\hline & stratum & linearity of navigation path (0-"bushy"navigation; 1-linear navigation) \\
\hline & t_per_click & navigation speed: average time per web page \\
\hline Time & duration & total time on each task \\
\hline
\end{tabular}

\section{Search Task Outcomes (TO)}


Three experts independently judged web pages that were bookmarked as relevant by the study participants. The experts assessed the relevance of the bookmarked documents and the extent to which a bookmarked document covered the answer to the question (part of answer). Employing three experts and taking their average responses objectified the assessments. The inter-rater agreement assessed by employing Intra-class Correlation Coefficient was good to very good. For relevance, the average Intra-class Correlation Coefficient was $0.73(\mathrm{~F}(725,1450)=3.72, \mathrm{p}<.001)$. For part of answer, the average Intra-class Correlation Coefficient was $0.86(\mathrm{~F}(727,1454)=7.23$, $\mathrm{p}<.001)$.

\section{Subjective variables (SU)}

Subjective variables were those that were self-reported by participants. They reflected perceptions of individual feelings, mental states, or reflected personal judgments of search task experience. These subjective variables were contrasted with the objective variables that were either controlled by experimenters (independent factors - IF), that were observable (search behavior measures - BE) or that were assessed by several independent experts (task outcomes TO). Thus, the objective variables related to conditions independent of individual thought, or were objectified by controlled experimental design and by using judgments of several observers.

Subjective user feelings and perceptions were collected by means of two questionnaires administered on a computer before and after each search task.

Before each task, participants were asked to assess:

- their level of happiness at this particular moment (before_happy);

- their familiarity with the search topic (before_familair);

- their interest in the search topic (before_interest);

- difficulty of the search task at hand (before_easy).

After each task, participants were asked to assess:

- their feelings (positive/negative) experienced during the search (after_feel);

- their confidence in the found results (after_confidence);

- their satisfaction with the search (after_satisfaction);

- whether they felt lost during the search task (after_lost);

- how difficult the search task was (after_easy).

Two questions were designed to prompt participants to report their feelings. Before the task we asked about their level of happiness. This question was included to monitor participants' wellbeing during the search. While the after-task "feeling" question is similar to the before-task "happiness" question, it is a retrospective measure of searchers recently experienced feelings. Appendix 1 lists questions used in the two questionnaires. The subjective variables are listed in Table 7.

Table 7. Summary of subjective variables (SU)

\begin{tabular}{ccc}
\hline Variable Group & Variable Name & Variable Scale \\
\hline Before Each Search & before_happy & 1=very unhappy / 5=very happy \\
\hline
\end{tabular}




\begin{tabular}{|c|c|c|}
\hline \multirow[t]{3}{*}{ (SU-before) } & before_easy & $1=$ very difficult $/ 5=$ very easy \\
\hline & before_interest & $1=$ not at all $/ 5=$ extremely interested \\
\hline & before_familiarity & $1=$ not at all $/ 5=$ extremely familiar \\
\hline \multirow{5}{*}{$\begin{array}{l}\text { After Each Search } \\
\text { (SU-after) }\end{array}$} & after_feel & $1=$ extremely negative $/ 5=$ extremely positive \\
\hline & after_easy & $1=$ very difficult $/ 5=$ very easy \\
\hline & after_confidence & $1=$ strongly disagree $/ 5=$ strongly agree \\
\hline & after_lost & $1=$ strongly disagree $/ 5=$ strongly agree \\
\hline & after_satisfacton & $1=$ very dissatisfied $/ 5=$ very satisfied \\
\hline
\end{tabular}

The number of questions that we could ask searchers' about their subjective states between the tasks was constrained by the number of search tasks performed and by the attempt to minimize interference with the subjective states (e.g., not to cause annoyance, etc.). We selected 'subjective' measures that were commonly used in previous research and that satisfied our goal of monitoring subjective states during the online search.

\section{Statistical Analyses.}

We conducted a number of Canonical Correlation Analysis (CCA) statistical tests that allowed us to correlate multiple dependent and multiple independent variables (Sherry \& Henson, 2005). The CCA method was chosen because it allows for measuring the linear relationship between two multidimensional variables (also referred to as synthetic variables). In the case of this study, the elemental dimensions of the synthetic variables are composed of subjective variables, behavioral variables, search outcomes variables, and the two controlled factors: task type and search system type. CCA finds two bases, one for each synthetic variable, that maximize correlations among the component dimensions (Borga, 2001). Advantages of CCA include reduced probability of making a Type I error (which usually increases when multiple tests are performed instead of a single multivariate test). The test allows examining multiple dependent and independent variables that represent complex relationships where variables can have multiple causes and multiple effects. CCA is also a comprehensive technique that has been demonstrated to subsume ANOVA, MANOVA, multiple regression, discriminant analysis and other tests (Henson, 2000).

When interpreting the CCA results, we examine the p-value to see if the model is statistically significant; we also examine Wilk's $\lambda$ to derive the effect size (effect size or $\operatorname{Rc}^{2}=1-\lambda$ ). When examining the contribution of measurable variables into the creation of the synthetic dependent and independent variables we interpret structure coefficients and function coefficients. Function coefficients are standardized coefficients that are used in the linear equations to combine the observed variable into the synthetic variable; function coefficients are analogous to beta weights in regression. Structure coefficient is the bivariate correlation between observed variable and a synthetic variable and is analogous to structure coefficient in multiple regression and factor analysis. The signs of structure coefficients inform interpretation of the relationships between the variables (e.g., negative sign indicates lower scores, fever actions, etc. while positive sign indicates higher scores, more actions, etc.) Squared structure coefficient is analogous to any $\mathrm{r}^{2}-$ type effect size and represents variance of a synthetic variable explained by an observed variable (Sherry \& Henson, 2005). 


\section{Results}

In interpreting the CCA, we focused on the statistically significant models and functions. Our description of the CCA functions is based on the interpretation of the variables that had the largest contribution to the synthetic criterion (dependents) and predictor (independents) functions (the variables with the function coefficients above .5 or the largest function coefficients relative to others) and high structure coefficients. It is worth noting that CCA method is based on correlations and does not necessarily imply causal relationships. However, our experimental design, the temporal sequence of events, and the relationships between variables supported by previous studies allows us to talk about directionality of relationships in the proposed model.

\section{Relationships between subjective and behavioral variables}

We examined relationships between subjective variables and searcher's behavior represented by search effort and efficiency. We used CCA to correlate variables representing searchers' subjective states measured between the search tasks (before_familiarity, before_interest, before_easy, before_happy, after_satisfaction, after_lost, after_confi, after_feel, after_easy) with variables representing search behavior and performance (bookmark, content pages, duration, total_pages, resList1_pages, revisit_ratio, stratum, t_per_click).

The analysis yielded eight functions, two of which were statistically significant with squared canonical correlation $\left(R_{C}{ }^{2}\right)$ of .410 for the first function and squared canonical correlation $\left(R_{C}{ }^{2}\right)$ of .104 for the second function resulting in the total $R_{C}{ }^{2}$ of .514 variance explained The full model across all functions was statistically significant using the Wilk's $\lambda=.45$ criterion, $F$ ( 72 , $1656.01)=3.246, p<.001$. The full model $r^{2}$ type effect size was .55 which indicated that all canonical functions explained about $55 \%$ of the variance shared between the variable sets. Second function was also statistically significant at $F(56,1470.08)=1.379, p<.035$.

Given the $R_{C}^{2}$ effects for each function, the first function explained about $41 \%$ of the shared variance and the second function explaining about $10 \%$ of the residual variance.

Table 8 presents the standardized canonical function coefficients (Coef), structure coefficients $\left(r_{s}\right)$ and squared structure coefficients, or communalities $\left(r_{s}{ }^{2}\right)$ for the interpreted functions.

Table 8. CCA of subjective variables and search effort/efficiency variables (SU and BE)

\begin{tabular}{cccc}
\hline Functions/Variables & $\begin{array}{c}\text { Function } \\
\text { coefficient (coef) }\end{array}$ & $\begin{array}{c}\text { Structure } \\
\text { coefficient }\left(\boldsymbol{r}_{\boldsymbol{s}}\right)\end{array}$ & $\begin{array}{c}\text { Communalities } \\
\left(\boldsymbol{r}_{\boldsymbol{s}} \mathbf{2}^{(\%)}\right)\end{array}$ \\
\hline Function 1: dependent synthetic variable & & & \\
\hline bookmark & -.499 & .172 & .03 \\
content_pages & .457 & $\mathbf{. 6 7 0}$ & .45 \\
duration & $\mathbf{. 5 4 7}$ & $\mathbf{. 8 2 5}$ & .68 \\
total_pages & -.130 & $\mathbf{. 7 5 5}$ & .57 \\
resList1_pages & .491 & $\mathbf{. 8 4 4}$ & .71 \\
\hline
\end{tabular}




\begin{tabular}{|c|c|c|c|}
\hline revisit_ratio & -.082 & .171 & .03 \\
\hline stratum & -.033 & -.343 & .12 \\
\hline t_per_click & -.067 & -.229 & .05 \\
\hline \multicolumn{4}{|c|}{ independent synthetic variable } \\
\hline before_familiarity & .237 & .320 & .10 \\
\hline before_interest & .287 & .321 & .10 \\
\hline before_easy & -.189 & -.173 & .03 \\
\hline before_happy & .280 & .216 & .05 \\
\hline after_easy & -.440 & -.827 & .68 \\
\hline after_satisfaction & -.048 & -.687 & .47 \\
\hline after_lost & .205 & .735 & .54 \\
\hline after_feel & -.122 & -.617 & .38 \\
\hline after_confidence & -.223 & -.518 & .27 \\
\hline \multicolumn{4}{|c|}{ Function 2: dependent synthetic variable } \\
\hline bookmark & -.743 & -.328 & .11 \\
\hline content_pages & .044 & .085 & .01 \\
\hline duration & .157 & .049 & .00 \\
\hline total_pages & 1.320 & .029 & .00 \\
\hline resList1_pages & -1.140 & -.437 & .19 \\
\hline revisit_ratio & -.611 & -.191 & .04 \\
\hline stratum & -.296 & .044 & .00 \\
\hline t_per_click & .275 & .381 & .15 \\
\hline \multicolumn{4}{|c|}{ independent synthetic variable } \\
\hline before_famililarity & .410 & .467 & .22 \\
\hline before_interest & -.082 & .180 & .03 \\
\hline before_easy & .008 & .361 & .13 \\
\hline before_happy & .223 & .348 & .12 \\
\hline after_easy & .342 & .176 & .03 \\
\hline after_satisfaction & -1.039 & -.291 & .08 \\
\hline after_lost & -.681 & -.322 & .10 \\
\hline after_feel & -.207 & -.113 & .01 \\
\hline after_confidence & .406 & .338 & .11 \\
\hline
\end{tabular}

Examination of function coefficients for the Function 1 suggests that the strongest criterion variable was duration. This conclusion was partially supported by structure coefficients. Tot_pages, resList1_pages, and content_pages variables had modest function coefficients but large structure coefficients, the result that can be attributed to the multicollinearity that these variables had with other criterion variables.

Judging by the function coefficients, the strongest contributor to the independent synthetic variable was after_easy. This conclusion was partially supported by structure coefficients. The variables after_satisfaction, after_lost, after_feel, after_confidence had modest function coefficients but large structure coefficients, the result that can be attributed to the multicollinearity that these variables had with other variables. The sign of the structure coefficient of after_easy was negative indicating that it was negatively related to the duration. In other words, tasks that took longer to complete were judged by searchers as more difficult.

Examination of function coefficients for the Function 2 suggests that the primary contributors to the criterion synthetic variable were bookmark, total_pages, resListl_pages, and revisit. This 
conclusion was only partially supported by the structure coefficients. Only resList1_pages had relatively high structure coefficient. Low structure coefficients of other variables with high function coefficients suggested that they might be suppressor variables that do not explain synthetic criterion variable, but help resList1_pages, a variable with the high function coefficient and high structure coefficient, in explaining the variance of the synthetic variable.

The strongest contributor to the independent synthetic variable, based on the function coefficients, was after_satisfaction and after_lost. This conclusion was only partially supported by the structure coefficients.

We chose to interpret variables that had high function coefficients but modest structure coefficients because they suggested interesting relationships between synthetic variables that are worth noting and possibly exploring in the future. Based on the signs of the structure coefficients, it appears that after_satisfaction and after_lost was positively related to bookmark, resList1_pages, and revisit, and negatively related to total_pages. In other words, searchers who visited more pages, but examined less result lists, made less revisits, and saved less bookmarks, felt less satisfied with the search, but at the same time reported feeling less lost during the search (for a more detailed interpretation, see Discussion).

\section{Relationships between subjective variables before the search and subjective variables after the search}

We investigated the general pattern of subjective variables by correlating pre-search subjective variables (before_familiarity, before_interest, before_easy, before_happy) and post-search subjective variables (after_easy, after_satisfaction, after_lost, after_confidence, after_feel).

The analysis yielded four functions, two of which were statistically significant with squared canonical correlation $\left(R_{C}{ }^{2}\right)$ of .15 for the first function, squared canonical correlation $\left(R_{C}{ }^{2}\right)$ of .9 for the second function. Given the $R_{C}{ }^{2}$ effects for each function, the first function explained about $15 \%$ of the shared variance, the second function explaining about $9 \%$ of the residual variance. The full model across all functions was statistically significant using the Wilk's $\lambda=.75$ criterion, $F(200,926.29)=4.151, p<.001$. The full model $r^{2}$ type effect size was .25 which indicated that all canonical functions explained about $25 \%$ of the variance shared between the variable sets. Second function was statistically significant at $F(12,741.10)=2.915, p<.001$. However, because the second function had very modest effect size, we did not interpret it.

Table 9 presents the standardized canonical function coefficients (Coef), structure coefficients $\left(r_{s}\right)$ and squared structure coefficients, or communalities $\left(r_{s}^{2}\right)$ for the one interpreted function.

Table 9. CCA of subjective states before and subjective states after the search (SU-before and SU-after)

\begin{tabular}{cccc}
\hline Functions/Variables & $\begin{array}{c}\text { Function } \\
\text { coefficient (coef) }\end{array}$ & $\begin{array}{c}\text { Structure } \\
\text { coefficient }\left(\boldsymbol{r}_{\boldsymbol{s}}\right)\end{array}$ & $\begin{array}{c}\text { Communalities } \\
\left(\boldsymbol{r}_{\boldsymbol{s}} \mathbf{2}(\mathbf{\%})\right)\end{array}$ \\
\hline Function 1: Independent synthetic variable & & \\
\hline after_easy & .148 & .597 & 0.36 \\
after_satisfaction & -.234 & .466 & 0.22 \\
after_lost & -.107 & -.483 & 0.23 \\
after_confience & .050 & .500 & 0.25 \\
after_feel & $\mathbf{. 9 5 9}$ & $\mathbf{. 9 8 4}$ & 0.97 \\
\hline
\end{tabular}




\begin{tabular}{cccc}
\hline Dependent synthetic variable & & & \\
\hline before_famililarity & -.060 & .283 & 0.08 \\
before_interest & .033 & .429 & 0.18 \\
before_easy & $\mathbf{. 6 5 8}$ & $\mathbf{8 7 1}$ & 0.76 \\
before_happy & $\mathbf{. 5 3 4}$ & $\mathbf{. 8 0 6}$ & 0.65 \\
\hline
\end{tabular}

The variable with the largest function coefficients to the criterion synthetic variable is after_feel. This conclusion is supported by the structure coefficients. The variables before_easy and before_happy had the largest function coefficients in forming the dependent synthetic variable. This conclusion is supported by the high structure coefficients. Because all the variables were positively related to each other, we can say that high scores on the before_easy and before_happy scales correlated with the high scores on the after_feel scale. In other words, searchers who felt happy and estimated the task to be easy before the search felt good after the search.

\section{Relationships between search task's type and subjective variables after the search task}

To investigate relationships between the search task type, the search system interface, and the subjective states after the search we correlated three independent variables (task type: q_SHP, q_FF_IG, and search system interface: ui) and five subjective variables collected after the search task completion (after_confidence, after_feel, after_lost, after_satisfaction, after_easy) The analysis yielded 3 functions, two of which were statistically significant with squared canonical correlation $\left(R_{C}^{2}\right)$ of .128 for the first function, squared canonical correlation $\left(R_{C}^{2}\right)$ of .5 for the second function. The full model across all functions was statistically significant using the Wilk's $\lambda=.823$ criterion, $F(15,773.36)=3.758, p<.001$. The full model $r^{2}$ type effect size was .177 which indicated that all canonical functions explained about $17.7 \%$ of the variance shared between the variable sets. Second function was statistically significant at $F(8,562.00)=2.023, p$ $<.05$.

Given the $R_{C}^{2}$ effects for each function, the first function explained about $12.8 \%$ of the shared variance, the second function explained only about $5 \%$, and we chose not to interpret it.

Table 10 presents the standardized canonical function coefficients (Coef), structure coefficients $\left(r_{s}\right)$ and squared structure coefficients $\left(r_{s}^{2}\right)$ for the only interpreted function.

Table 10. CCA of task type and subjective variables after the task (IF and SU-after)

\begin{tabular}{cccc}
\hline Functions/Variables & $\begin{array}{c}\text { Function } \\
\text { coefficient (coef) }\end{array}$ & $\begin{array}{c}\text { Structure } \\
\text { coefficient }\left(\boldsymbol{r}_{\boldsymbol{s}}\right)\end{array}$ & $\begin{array}{c}\text { Communalities } \\
\left(\boldsymbol{r}_{\boldsymbol{s}} \mathbf{2}(\mathbf{\%})\right)\end{array}$ \\
\hline Function 1: Independent synthetic variable & & & \\
\hline after_easy & $\mathbf{. 7 8 8}$ & $\mathbf{9 8 2}$ & .96 \\
after_satisfaction & -.071 & $\mathbf{. 7 2 0}$ & .52 \\
after_lost & -.161 & $\mathbf{- . 7 6 8}$ & .59 \\
after_feel & .149 & $\mathbf{. 6 9 3}$ & .48 \\
after_confidence & .086 & $\mathbf{. 6 3 6}$ & .40 \\
\hline Dependent synthetic variable & & & .34 \\
qui & $\mathbf{- . 5 9 8}$ & $\mathbf{- . 5 8 0}$ & .56 \\
\hline
\end{tabular}


The strongest criterion variable with the largest function coefficient was after_easy and the strongest predictor variables with the largest function coefficients were ui and q_SHP. This conclusion was supported by the structure coefficients. The fact that all structure coefficients of the independent variable were relatively large attests to the multicollinearity between the variables. The same observation is valid for the structure coefficients of the variables contributing to the dependent synthetic variable. The model suggests that the use of a familiar search interface (-ui) and the tasks with a simpler structure ( - q_SHP) were associated with evaluations of searches as "easy" after the search completion.

\section{Relationships between subjective variables and search outcomes}

To examine relationships between subjective variables collected during the search and the search outcomes, we correlated subjective variables (before_familiarity, before_interest, before_easy, before_happy after_easy, after_satisfaction, after_lost, after_confidence, after_feel) with search outcomes variables (relevance, part_of_answer).

The analysis yielded two functions, one of which was statistically significant with squared canonical correlation $\left(R_{c}{ }^{2}\right)$ of .166 . The full model across all functions was statistically significant using the Wilk's $\lambda=.826$ criterion, $F(18,538.00)=3.005, p<.001$. The full model $r^{2}$ type effect size was .174 which indicated that all canonical functions explained about $17.4 \%$ of the variance shared between the variable sets. Second function was not statistically significant at $F(8,270.00)=4.939, p>.940$, yielded the squared canonical correlation $\left(R_{c}^{2}\right)$ of .010 and was not interpreted.

Table 11 presents the standardized canonical function coefficients (Coef), structure coefficients $\left(r_{s}\right)$ and squared structure coefficients $\left(r_{s}{ }^{2}\right)$ for the only interpreted function.

Table 11._CCA of subjective variables and task outcomes (SU and TO)

\begin{tabular}{|c|c|c|c|}
\hline Functions/Variables & $\begin{array}{c}\text { Function } \\
\text { coefficient (coef) }\end{array}$ & $\begin{array}{c}\text { Structure } \\
\text { coefficient }\left(r_{s}\right)\end{array}$ & $\begin{array}{l}\text { Communalities } \\
\left(r_{s}{ }^{2}(\%)\right)\end{array}$ \\
\hline \multicolumn{4}{|c|}{ Function 1: Independent synthetic variable } \\
\hline before_famililarity & -.246 & -.177 & .03 \\
\hline before interest & .189 & .070 & .00 \\
\hline before_easy & .147 & .226 & .05 \\
\hline before_happy & -.532 & -.277 & .08 \\
\hline after_satisfaction & .224 & .748 & .56 \\
\hline after_easy & .039 & .670 & .45 \\
\hline after_lost & -.123 & .551 & .30 \\
\hline after_confidence & .323 & -.665 & .44 \\
\hline after feel & .404 & .767 & .59 \\
\hline
\end{tabular}




\begin{tabular}{rlll} 
relevance & .334 & .724 & .52 \\
part_of_answer & .792 & .957 & .92 \\
\hline
\end{tabular}

The strongest criterion variable, judged by the function coefficients, was before happy. This conclusion was only partially supported by structure coefficients. In fact, the following variables collected after search had relatively high structure coefficients, after_satisfaction, after_easy, after_lost, after_confi and after_feel, suggesting that they were highly correlated with one another (multicollinearity).

The variable with the largest function coefficient contributing to the dependent synthetic variable was part_of_answer. This conclusion was supported by the structure coefficient. Relevance variable also had a large structure coefficient, pointing to the multicollinearity between the variables. The finding suggests that participants who felt unhappy before the search found more complete, and judging by the structure coefficients, more relevant Wikipedia pages. If we add to this interpretation of the variables that have large structure coefficients with the independent synthetic variable, we can say that searchers who found more complete and relevant pages reported feeling good, more satisfied, less lost, less confident in results and, at the same time, they assessed the task a posteriori as more difficult.

\section{Discussion}

This section discusses moderately strong and strong relationships that were uncovered by the CCA statistical tests. Results of the tests are summarized in Table 12. The paragraphs in the discussion below are numbered according to the row numbers in Table 12.

Table 12._Summary of results ( $R N$ is a Relationship Number)

\begin{tabular}{|c|c|c|c|c|c|}
\hline$\#$ & $\begin{array}{l}\text { Index } \\
\text { (Table 1) } \\
\end{array}$ & $\begin{array}{l}\text { Variable } \\
\text { Group }\end{array}$ & $\begin{array}{r}\text { (Strong) Relatic } \\
\text { varia }\end{array}$ & $\begin{array}{l}\text { ships among } \\
\text { les }\end{array}$ & Short Interpretation \\
\hline 1 & $\bar{e}$ & $\begin{array}{r}\mathrm{SU} \& \mathrm{BE}- \\
\text { relationship 1 }\end{array}$ & duration & -after_easy & $\begin{array}{l}\text { tasks that took longer to perform } \\
\text { were also judged as more difficult }\end{array}$ \\
\hline 2 & e & $\begin{array}{l}\mathrm{SU} \& \mathrm{BE}- \\
\text { relationship } 2\end{array}$ & $\begin{array}{r}- \text { bookmark, } \\
\text { - resList1_pages, } \\
- \text { revisit } \\
\text { total_pages }\end{array}$ & $\begin{array}{r}\text {-after_satisfaction } \\
\text { - after_lost }\end{array}$ & $\begin{array}{l}\text { searchers who visited more pages, } \\
\text { examined less result pages, revisited } \\
\text { less pages, and saved less bookmarks } \\
\text { felt less satisfied with the search, but } \\
\text { also less lost during the search }\end{array}$ \\
\hline 3 & $\mathrm{c}$ & $\begin{array}{l}\text { SU-before } \\
\& \text { SU-after }\end{array}$ & $\begin{array}{r}\text { before_easy } \\
\text { before_happy }\end{array}$ & after_feel & $\begin{array}{l}\text { searchers who felt happy and } \\
\text { estimated the task to be easy before } \\
\text { the search felt good after the search }\end{array}$ \\
\hline 4 & $f, g$ & $\begin{array}{r}\text { IF \& } \\
\text { SU-after }\end{array}$ & $\begin{array}{r}- \text { ui } \\
- \text { q_SHP }\end{array}$ & after_easy & $\begin{array}{l}\text { searches on familiar search interface } \\
\text { and with simpler structure were } \\
\text { evaluated as easy after the search } \\
\text { completion }\end{array}$ \\
\hline 5 & b, d & SU \& TO & $\begin{array}{r}\text { - before_happy } \\
\text { (after_satisfaction } \\
\text { after_easy } \\
\text { after_lost } \\
\text { - after_confidence } \\
\text { after_feel) }\end{array}$ & $\begin{array}{l}\text { part_of_answer } \\
\text { relevance }\end{array}$ & $\begin{array}{l}\text { searchers who felt unhappy before the } \\
\text { search, and who found more } \\
\text { complete and relevant pages, reported } \\
\text { feeling more satisfied, happier, less } \\
\text { lost, less confident in results and } \\
\text { assessed the task to be more difficult } \\
\text { after the search }\end{array}$ \\
\hline
\end{tabular}


1. The correlation of subjective (before/after search) and behavioral variables suggested that tasks that took longer to complete tended to be judged as more difficult after the search. This finding suggests that a posterior assessment of search task difficulty is correlated with the amount of time it takes to complete the task: the longer it takes to complete the search task, the more difficult it seems after the search. This finding is intuitively well understood and supported by previous studies that linked search duration with task difficulty assessment (Gwizdka \& Spence, 2006, 2007). It is somewhat surprising that searchers' a priori estimations of task difficulty were not correlated with the time it took them to complete the task, indicating that, perhaps, searchers were unable to make accurate predictions about the task difficulty before engaging in the search. While we did not find LIS literature supporting this observation, it can be supported by the psychological research in inaccuracies of human predictions about the future events (Loewenstein \& Schkade, 1999).

2. The correlation between subjective (before/after search) and behavioral variables also suggested that searchers who visited more pages, examined less search result pages, revisited less pages, and saved less bookmarks, reported feeling less satisfied with the search, but at the same time reported feeling less lost during the search. The search strategy when people issue less queries, but visit more pages (possibly by following links from one page to another), and rarely revisit what they have seen earlier, appears to be less effective and leads to fewer relevant results saved. The finding that the less effective strategy and fewer relevant results saved lead to lower satisfaction is supported by previous research (Bilal \& Kirby, 2002; Wang, et al., 2000). The original finding of our study is that people who used less effective search strategy also felt less lost during the search. Feeling less lost may be partially explained by the low ratio of revisits, so it is possible that people using this strategy feel less need to revise their searches as they believe that they can find information by following links between related web pages. This finding also confirms that the analytic measures (i.e. the revisit ratio) are well correlated with subjective perception of lostness (Gwizdka \& Spence, 2007; Otter \& Johnson, 2000). We can also hypothesize that not feeling lost during the search does not lead to higher satisfaction and better search outcomes, suggesting that, perhaps, it pays off to feel some 'pain' during the search in order to 'gain' quality outcomes. This "no pain, no gain" conjecture was supported by the results from another study conducted by one of the authors (Lopatovska, 2009b).

In our discussion of the correlations between subjective and behavioral variables, we note that certain behavioral variables (content_pages, total_pages, resList1_pages, duration) and subjective variables (after_easy, after_satisfaction, after_lost, after_feel, after_confidence) are highly inter-correlated and are grouped by the underlying structure (multicollinearity issues are discussed in the Results section). This result suggests that searchers who spent more time on the task also visited more pages in total, visited more individual results pages and entered more queries. The multicollinearity between subjective variables suggests that searchers who felt lost during the search, judged the task to be more difficult after the search and felt better, more satisfied and more confident in search results. Also, we have not found correlation between the subjective user's state before a search task and the user's search behavior indicating that participants' feelings and perceptions before the search did not impact their search behaviors. 
3. The correlation of subjective states before the search task and subjective states after the search task revealed that searchers who estimated the task to be easy and who felt happy before the search felt better after the search. This finding is in line with the research that shows a link between optimism prior to search and better mood after the search (Nahl, 2004). It also confirms the findings that the mood measured before the search and after the search does not change significantly and is not significantly influenced by the search process (Lopatovska, 2009a).

4. The examination of relationships between the task type, search engine type, and the postsearch subjective variables suggests that search tasks that had a simpler structure and were performed using the more familiar search engine tended to be evaluated as easy after the search completion. This finding is intuitively well understood: more familiar and simpler tasks are judged as being easier after the search. The finding is consistent with the prior research. For example, Meghabghab (1995) showed that positive feelings increased as searchers gained familiarity with the search process; Arapakis, Jose and Gray (2008) showed that the task difficulty was directly linked to emotion valence.

5. Analysis of the relationships between subjective variables and search outcomes indicates that searchers who felt less happy before the search tended to have better task outcomes (in a sense of saving more relevant Web pages that more fully addressed the search question). After the search task, these searchers assessed the task as more difficult, reported feeling more satisfied, happier, less lost, but also less confident. In other words, situations in which searchers started the task in an unhappy state, felt more in control during the search and completed the task better, tended to induce a positive feelings and a higher satisfaction after the search. This finding might suggest that participants' search actions are at least partially guided by the desire to change their current affective state to a more desired one, which means that those who start the search feeling less happy are more motivated to change their current state by succeeding in the search task (versus the participants who feel good before the search and do not want to change the status quo by investing effort into the thorough searching). This exploratory finding is in line with one of the author's other study findings (Lopatovska, 2009a). Alternatively, this finding might suggest that performance is influenced by personality differences and that 'pessimists' are better searchers. Personality differences would also explain why searchers who felt less happy before the search also felt less confident in their search results (perhaps because they have higher standards for personal performance which motivated them to achieve better results). These hypotheses need further investigation by incorporating personality-type measures into the study design. 


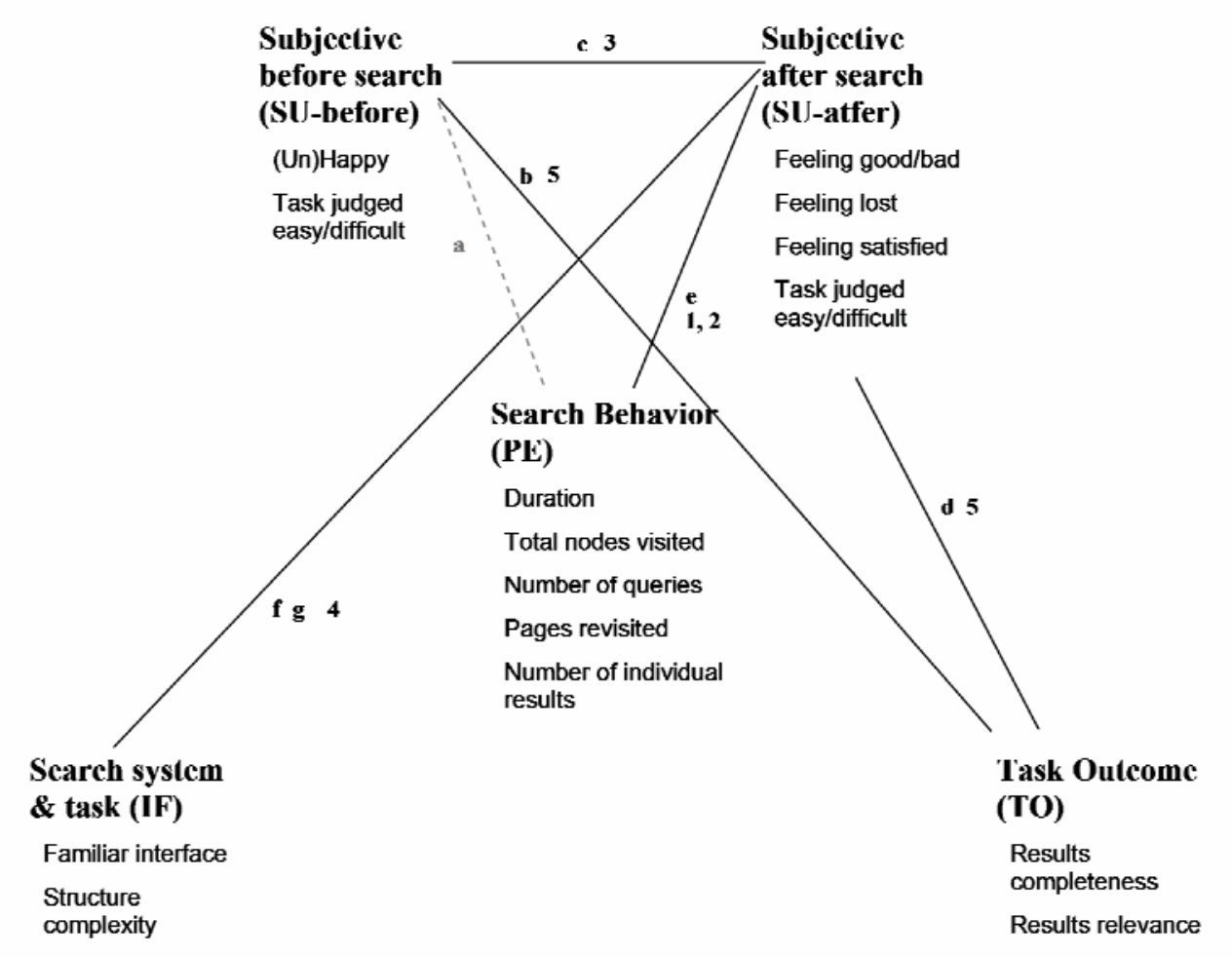

Figure 3. Role of Subjective Variables in the Information Search Process - a revised model based on our results. The numbers next to the lines refer to the index numbers in the summary Table 12. The letters refer to the relationships discussed in the Related Research section.

\section{Conclusions}

Our study investigated the role of subjective variables in the information search process in an online environment of the World Wide Web. We examined the relationships between subjective variables, search behavior, search outcomes, characteristics of the search task and familiarity with the search system and its interface.

The study limitations include use of convenience sample where participants' Internet experience, background and age were very similar. This fact makes our finding generalizable to a relatively small portion of student population. Another limitation of the study is the use of tasks that appeared to be relatively easy for the studied population sample. While the tasks were designed to differ in difficulty, more than a half of task instances were judged as relatively easy by participants. It would be interesting to examine if more difficult tasks had different effect on searchers' subjective experiences.

The study used two search engines (Google, Alvis) to find information on the same web-based system (Wikipedia). Further studies should investigate whether the current findings hold during interactions with other kinds of information systems. And, finally, the study investigated a limited set of subjective variables; hence the findings are limited to these few selected subjective factors. Future work will verify current findings and focus on the role of specific subjective states (e.g., mood, perceptions, affect) in the search process. 
The study used Canonical Correlation Analysis, a statistical technique that is infrequent in the Library and Information Science research. We found this data analysis method to be very appropriate for examining complex relationships between multiple dependent and multiple independent variables, and recommend its use in the future studies.

The conceptual framework (Figure 1) guided the selection of relationships that we examined. We examined some unique combinations of variables that were individually studied in the past but not in the combination we designed for the study. While we confirmed most of the high-level relationships shown in Figure 1, some of the relationships between individual variables that we studied were unique. The specific variables that we investigated did not confirm relationship between subjective measures before search and search behavior (that is, relationship labeled "a" in Figure 3).

The findings confirm some previous results as well as extend them (Figure 3). For example, we found the link between objective search task difficulty (e.g., the amount of time spent on the task, number of pages visited, etc.) and the perception of task difficulty; the link between the mood and search behavior and outcomes. All these findings are inline with the previous research on the role of subjective factors in information seeking.

Our original findings suggest that better mood before the search and during the search correlate with better mood after the search, but also correlates with a worse search outcomes and lower satisfaction. We based our analysis on statistical correlations. The effects of controlled factors (relationship \#4 in Table 12 and Figure 3), and the relationships between variables with a strictly defined order in time (relationship \#1-3,5) allow us to talk about plausible causal effects. If causal relationships are verified, the finding implies that mood might be a major predictor of search outcomes (regardless of the task or the interface) and individual differences between the searchers (optimists vs. pessimists, searchers experiencing positive vs. negative affective states, etc.) might have a major effect on search outcomes. To a certain degree, this finding also questions the efforts to design 'pleasurable' search experiences since feeling good during the search does not seem to translate into the better outcomes. Due to the potential importance of these findings, they should be further investigated and validated.

\section{Acknowledgements}

This research has been supported in part by a grant from Rutgers University Research Council. We thank anonymous reviewers for their valuable comments. 


\section{Appendix}

\section{Pre-search-task questions}

How familiar are you with the topic of the search task?
No at all
A little bit Somewhat Familiar
Very
Extremely

How interesting do you find the topic of the search task?

No at all A little bit Somewhat Interested Very Extremely

How easy do you think it will be to find information for this task?

Very Easy Easy Neutral Difficult Very Difficult

How happy are you right now?

Extremely Unhappy Unhappy Neutral Happy Extremely Happy

\section{Post-search-task questions}

How did you feel during the search?
Extremely Negative Negative
Neutral
Positive
Extremely Positive

I am confident that I found the desired information. Strongly Agree Agree Neutral Disagree Strongly Disagree

I was lost at some point during this search. Strongly Agree Agree Neutral Disagree Strongly Disagree

Did you find it easy or difficult to do this search task? Very Easy Easy Neutral Difficult Very Difficult

Please rate your overall satisfaction with this search experience. Very Satisfied Satisfied Neutral Dissatisfied Very Dissatisfied

Table 13. Example search tasks used in the study (one for each combination of task type and structure).

\begin{tabular}{cl}
\hline Type & \multicolumn{1}{c}{ Question text } \\
\hline FF-S & $\begin{array}{l}\text { You love history and, in particular, you are interested in the Teutonic Order (Teutonic Knights). You } \\
\text { have read about their period of power, and now you want to learn more about their decline. What } \\
\text { year was the Order defeated in a battle by a Polish-Lithuanian army? }\end{array}$ \\
\hline FF-H & $\begin{array}{l}\text { A friend has just sent an email from an Internet café in the southern USA where she is on a hiking } \\
\text { trip. She tells you that she has just stepped into an anthill of small red ants and has a large number } \\
\text { of painful bites on her leg. She wants to know what species of ants they are likely to be, how } \\
\text { dangerous they are and what she can do about the bites. What will you tell her? }\end{array}$ \\
\hline FF-P & $\begin{array}{l}\text { As a history buff, you have heard of the quiet revolution, the peaceful revolution and the velvet } \\
\text { revolution. For a skill-testing question to win an iPod you have been asked how they differ from the } \\
\text { April 19th revolution. }\end{array}$ \\
\hline IG-H & $\begin{array}{l}\text { You recently heard about the book "Fast Food Nation," and it has really influenced the way you think } \\
\text { about your diet. You note in particular the amount and types of food additives contained in the things } \\
\text { that you eat every day. Now you want to understand which food additives pose a risk to your physical } \\
\text { health, and are likely to be listed on grocery store labels. }\end{array}$ \\
\hline $\begin{array}{l}\text { Friends are planning to build a new house and have heard that using solar energy panels for heating } \\
\text { can save a lot of money. Since they do not know anything about home heating and the issues } \\
\text { involved, they have asked for your help. You are uncertain as well, and do some research to identify } \\
\text { some issues that need to be considered in deciding between more conventional methods of home } \\
\text { heating and solar panels. }\end{array}$ \\
IG-P
\end{tabular}




\section{References}

Agosto, D. E. (2002). Bounded Rationality and Satisficing in Young People's Web-Based Decision Making. Journal of the American Society for Information Science,53(1), 16-27.

Arapakis, I., Jose , J.M. \& Gray, P.D. (2008). Affective feedback: An investigation into the role of emotions in the information seeking process. Proceedings of the $31^{\text {st }}$ annual international ACM SIGIR conference on Research and development in information retrieval, New York, USA, 395-402

Bilal, D. \& Bachir, I. (2007). Children's interaction with cross-cultural and multilingual digital libraries. II. Information seeking, success, and affective experience. Information Processing and Management, 43, 65-80.

Bilal, D. \& Kirby, J. (2002). Differences and similarities in information seeking: Children and adults as web users. Information Processing and Management, 38, 649-670.

Bilal, D. (2000). Children's use of the Yahooligans! web search engine: I. Cognitive, physical, and affective behavior on fact-based search tasks. Journal of the American Society for Information Science, 51(7), 646-665.

Bilal, D. (2002). Children's use of the Yahooligans! web search engine: III. Cognitive and physical, and affective behavior fully self-generated search tasks. Journal of the American Society for Information Science, 53(73), 1170-1183.

Borga, M. (2001). Canonical Correlation. A Tutorial. Retrieved February 10, 2009, from http://people.imt.liu.se/ ${ }^{2}$ magnus/cca/.

Borlund, P. (2003). The IIR evaluation model: A framework for evaluation of interactive information retrieval systems. Information Research, 8(3), paper no. 152. Retrieved February 1, 2009, from http://informationr.net/ir/8-3/paper152.html

Botafogo, R. A., Rivlin, E., \& Shneiderman, B. (1992). Structural analysis of hypertexts: Identifying hierarchies and useful metrics. ACM Transactions on Information Systems, 10, 142-180.

Buntine, W., Valtonen, K., \& Taylor, M. (2005, May). The ALVIS Document Model for a Semantic Search Engine. Paper presented at the 2nd Annual European Semantic Web Conference, Heraklion, Crete.

Gwizdka, J. \& Spence, I. (2006). What Can Searching Behavior Tell Us About the Difficulty of Information Tasks? A Study of Web Navigation. Proceedings of the 69th Annual Meeting of the American Society for Information Science and Technology, Austin, TX,3.

Gwizdka, J. \& Spence, I. (2007). Implicit Measures of Lostness and Success in Web Navigation. Interacting with Computers. 19(3). 357-369.

Henson, R. K. (2000). Demystifying parametric analyses: Illustrating canonical correlation as the multivariate general linear model. Multiple Linear Regression Viewpoints, 26(1), 11-19.

Herder, E. \& Juvina, I. (2004). Discovery of Individual User Navigation Styles. In G. D. Magoulas \& S.Y. Chen (Eds.), Adaptive Hypermedia AH2004 Workshop on Individual Differences in Adaptive Hypermedia. Eindhoven, The Netherlands.

Kahneman, D. (2000). Experienced utility and objective happiness: A moment-based approach. In D. Kahneman \& A. Tversky (Eds.) Choices, Values, and Frames (pp. 673-692). New York: Cambridge University Press. 
Kellar, M., Watters, C., \& Shepherd, M. (2007). A field study characterizing Web-based informationseeking tasks. Journal of the American Society for Information Science and Technology, 58(7), 999-1018.

Kracker, J. (2002). Research anxiety and students' perceptions of research: An experiment. Part I. Effect of teaching Kuhlthau's ISP model. Journal of the American Society for Information Science, 53(4), 282-294.

Kracker, J. \& Wang, P. (2002). Research anxiety and students' perceptions of research: An experiment. Part II. Content analysis of their writings on two experiences. Journal of the American Society for Information Science, 53(4), 295-307.

Kuhlthau, C. C. (1991). Inside the search process: Information seeking from the user' perspective. Journal of the American Society for Information Science, 42(5), 361-371.

Li, Y., \& Belkin, N. J. (2008). A faceted approach to conceptualizing tasks in information seeking. Information Processing \& Management, 44(6), 1822-1837.

Loewenstein, G. \& Schkade, D. (1999). Wouldn't it be nice? Predicting future feelings. In D. Kahneman, E. Diener, \& N. Schwarz (Eds.), Well-Being: The foundations of hedonic psychology (pp. 85-105). New York, NY: Russell Sage Foundation.

Lopatovska, I. (2009a). Does the mood matter? To appear in the Proceedings of the 2009 International Conference on Affective Computing and Intelligent Interaction.

Lopatovska, I. (2009b). Searching for good mood: Examining relationships between search task and mood. To appear in the Proceedings Annual Meeting of the American Society for Information Science and Technology, 2009.

Lopatovska, I. \& Mokros, H. (2007). Willingness to pay and experienced utility as measures of affective value in the information retrieval objects: Users' accounts. Information Processing and Management, 44(1), 92-104.

Marchionini, G. (1995). Information Seekers and Electronic Environments. In Information Seeking in Electronic Environments (pp. 11-26), Cambridge, MA: Cambridge University Press.

McEneaney, J. E. (2001). Graphic and numerical methods to assess navigation in hypertext. International Journal of Human Computer Studies, 55, 761-786.

Meghabghab, D. B. (1995). CD-ROM vs. online vs. Internet: Search strategies and evaluation from the user's perspective. E. Williams (Ed.), Proceedings of the 16th national online meeting, May 2-4, 1995, New York (pp. 295-307), Medford, NJ: Learned Information.

Mellon, C. A. (1988). Attitudes: The forgotten dimension in library instruction. Library Journal 113(14), 137-139.

Nahl, D. (1998). Learning the Internet and the structure of information behavior. Journal of the American Society for Information Science, 49(11), 1017-1023.

Nahl, D. (2004). Measuring the affective information environment of web searchers. Proceedings of the $67^{\text {th }}$ Annual Meeting of the American Society for Information Science and Technology Annual Meeting (41), 191-197.

Nahl, D. (2005). Affective and Cognitive Information Behavior: Interaction Effects in Internet Use. In A. Grove, (Ed.), Proceedings 68th Annual Meeting of the American Society for Information Science and Technology (42). Medford, NJ: Information Today. 
Nahl, D. \& Meer, M. P. (1997) User-Centered Assessment of Two Web Browsers: Errors, Perceived SelfEfficacy, and Success. Proceedings of the Annual Meeting of the American Society for Information Science Annual Meeting,(34), 89-97.

Nahl, D., \& Tenopir, C. (1996). Affective and cognitive searching behavior of novice end-users of a fulltext database. Journal of the American Society for Information Science, 47(4), 276-286.

Onwuegbuzie, A. J. \& Jiao, Q. G. (2004). Information search performance and research achievement: An empirical test of the Anxiety-Expectation Mediation model of library anxiety. Journal of the American Society for Information Science, 55(1), 41-54.

Otter, M. \& Johnson, H., (2000). Lost in hyperspace: Metrics and mental models. Interacting with Computers, 13, 1-40.

Redelmeier, D. \& Kahneman, D. (1996). Patients' memories of painful medical treatments: Real-time and retrospective evaluations of two minimally invasive procedures. Pain, 66, 3-8.

Saracevic, T. (2007). Relevance: A review of the literature and a framework for thinking on the notion in information science. Part II: Nature and manifestations of relevance. Journal of the American Society for Information Science and Technology, 58(3), 1915-1933.

Schkade, D. A., \& Kahneman, D. (1998). Does living in California make people happy? A focusing illusion in judgments of life satisfaction. Psychological Science, 9, 340-346.

Schreiber, C. A., \& Kahneman, D. (1996). Beyond the peak and end hypothesis: Exploring the relation between real-time displeasure and retrospective evaluation. Working paper, Princeton University.

Sherry, A., \& Henson, R. K. (2005). Conducting and interpreting canonical correlation analysis in personality research: A user-friendly primer. Journal of Personality Assessment, 84, 37-48.

Shih, P.-C., Mate, R., Sanchez, F., \& Munoz, D. (2004). Quantifying user-navigation patterns: A methodology proposal. Poster presented at the 28th International Congress of Psychology, Bejing, China.

Su, L. T. (2003). A comprehensive and systematic model of user evaluation of web search engines: I. Theory and background. Journal of the American Society for Information Science and Technology, 54(13), 1175-1192.

Tauscher, L. \& Greenberg, S. (1997). How people revisit web pages: Empirical findings and implications for the design of history systems. International Journal of Human Computer Studies, 47, 97-137.

Tessier, J. A., Crouch, W. W., \& Atherton, P. (1977). New measures of user satisfaction with computerbased literature searches. Special Libraries, 68(11), 383-389.

Toms, E., O’Brien, H., Mackenzie, T., Jordan, C., Freund, L., Toze, S. (2008). Task Effects on Interactive Search: The Query Factor. Workshop Pre-Proceedings In Initiative for the Evaluation of XML Retrieval (INEX) 2007, 359-372.

Tzeng, J.-Y. (2004). Toward a more civilized design: Studying the effects of computers that apologize. International Journal of Human-Computer Studies, 61(3), 319-345.

Wang, P., Hawk, W. B., \& Tenopir, C. (2000). Users' interaction with World Wide Web resources: An exploratory study using a holistic approach. Information Processing and Management, 36, 229-251. 